Check for updates

Cite this: RSC Adv., 2019, 9, 19189

Received 3rd April 2019

Accepted 11th June 2019

DOI: 10.1039/c9ra02521a

rsc.li/rsc-advances

\section{Correlation between lipophilicity of newly synthesized ionic liquids and selected Fusarium genus growth rate $\uparrow$}

\author{
Milan Vraneš, (D) a Aleksandar Tot, (D) *a Jasenka Ćosić, Snežana Papović, \\ Jovana Panić, ${ }^{a}$ Slobodan Gadžurić, iD a Nenad Janković iD c and Karolina Vrandečićb
}

\section{Introduction}

Fusarium genera contain over 1000 species, some of which are recognized as serious pathogens that colonize plants and produce various mycotoxins. ${ }^{\mathbf{1 2}}$ These filamentous fungi are widespread and cause a wide range of diseases with devastating yield quantity and quality losses. ${ }^{3}$ Fusarium culmorum (W. G. Smith) Sacc. and Fusarium oxysporum Schl. are among the most destructive Fusarium species and play an essential role in the etiology of a wide range of cereal, arable crop, fruit, ornamental and vegetable diseases. ${ }^{4} \mathrm{~F}$. culmorum is a soil-borne pathogen and one of the most important corn and small-grain cereal pathogens in the cooler temperate climates of Europe, Australia, West Asia, and North Africa. In addition, these species also infect numerous other monocotyledonous and dicotyledonous plant species such as potato, watermelon, carnation, gladiolus, etc. F. oxysporum is soil-borne species complex distributed all over the world which consists of pathogenic and nonpathogenic strains. Pathogenic strains infect almost 150 plant species including the most important cultivated crops:

${ }^{a}$ Faculty of Sciences, Department of Chemistry, Biochemistry and Enviromental Protection, University of Novi Sad, Trg Dositeja Obradovića 3, 21000, Novi Sad, Serbia. E-mail: aleksandar.tot@dh.uns.ac.rs; Fax: +38121454 065; Tel: +38121 4852744

${ }^{b}$ Faculty of Agrobiotechnical Sciences in Osijek, University of Josip Juraj Strossmayer in Osijek, Vladimira Preloga 1, 31000 Osijek, Croatia

${ }^{c}$ Department of Chemistry, University of Kragujevac, Faculty of Science, Radoja Domanovića 12, 34000 Kragujevac, Serbia

$\dagger$ Electronic supplementary information (ESI) available: MS, NMR and IR spectra of the newly synthesized ionic liquids. See DOI: 10.1039/c9ra02521a wheat, corn, rice and arable crops., ${ }^{2,5,6}$ Integrated plant protection, which includes agronomic techniques, chemical control and the growth of resistant genotypes, is probably the most effective approach to control Fusarium diseases. To avoid the possible development of fungal resistance and preserve the natural ecosystems and the health of consumers, we need to reduce the use of synthetic fungicides as much as possible. ${ }^{7,8}$

Within the last decade, ionic liquids (ILs, currently defined as salts melting below $100^{\circ} \mathrm{C}$ ) have been studied for a various number of applications where reduced toxicity is demanded., ${ }^{\mathbf{9} 10}$ The main reason to favor ionic liquids as green solvents was low vapor pressure leading to insignificant environmental impact on air. ${ }^{11-13}$ However, with rise of scientific interest in ILs, their environmental friendly potential become more and more under question. ${ }^{14-19}$ Nowadays, the established opinion about their "greenness" is that IL properties must be assessed on a case-bycase basis. According to this concept, the most promising strategy is the use of renewable resources for the synthesis of ILs. The potential of incorporation the well-known biological active ions in ionic liquids can lead to new possible applications. For example, the antimicrobial properties inherent to some ILs have been recognized as valuable tools for biocide applications, including the development of bioactive coatings against different pathogens, antiseptics, antifouling or anticancer agents. ${ }^{20-23}$ The promising field that can have operational benefits from a combination of biological activity and IL is agrochemistry. ${ }^{24}$ For instance, a hydrophobic IL form of an agrochemical could improve rain-fastness, reduce drift and the number of chemicals which need to be applied. Increased curative activity against plant pathogens might result from re- 
distribution into plant tissue since, in the absence of translaminar or systemic movement, a fungicide can only act on the target pathogen before it penetrates plant cell.

Additionally, the combination of active cation and anion in one IL formulation might lead to synergistic or antagonistic effects (as observed for pharmaceutically active ILs) which might even be used to overcome resistance..$^{15,25,26}$ The strategy to optimize and control the antifungal activity of ILs is incorporation in their structure compounds that are already commercially proven in the treatment of fungi. ${ }^{27-29}$ With this purpose, short chain $\omega$-phenylalcanoic/phenylalcenoic acids (mandelic, cinnamic and caffeic) were used as an anionic component in this work.

However, the complete mechanism of antifungal action for ILs remains unknown, although the most promising quantitative descriptor of antimicrobial activity currently indicates the surface activity. The molecular simulation studies of ionic liquid-biomembrane interactions show the spontaneous insertion of cations into the lipid bilayer. The insertion takes place regardless of the substituent (alkyl chain length and polarity), and it changes the structural and dynamic properties of the bilayer, which is the cause of its disruption. With a goal to examine the toxic effect of different ILs constituents, as well as to find a correlation between toxicity and structural properties, in this work, the antifungal activities of 23 synthesized ionic liquids were tested against Fusarium culmorum and Fusarium oxysporum.

\section{Materials and methods}

\subsection{Synthesis}

The provenance and purity of reagents used for the synthesis of ionic liquids are given in Table S1 in ESI $\dagger$ of this manuscript. The preparation of ILs with the desired anion was performed using a three-step strategy.

In the first step, ionic liquids with halide anions were synthesized and used as starting compounds for further synthesis. The procedure was based on the reaction of SN2 substitution of adequate heterocycle with appropriate alkylhalide or halogenated alcohols. The synthesis of 1-(3hydroxypropyl)-3-methylimidazolium chloride was described in our previous paper, ${ }^{30}$ while 1-butyl-3-methylimidazolium chloride was purchased. For the synthesis of pycoline based ionic liquids, $0.1 \mathrm{~mol}$ of methyl- $n$-pycoline and $0.11 \mathrm{~mol}$ of halogenoalkane (1-bromobutane or 3-chloro-1-propanol) was dissolved in toluene in the round bottom flask. The reaction was conducted under atmospheric pressure at a temperature of $125{ }^{\circ} \mathrm{C}$ for $72 \mathrm{~h}$. After the completion of reaction, toluene was removed by vacuum. Ionic liquid was washed with ethyl-acetate to remove potential unreacted starting compounds. Afterward, the remained solvents were removed using a vacuum and ILs were stored under $\mathrm{P}_{2} \mathrm{O}_{5}$ for next $48 \mathrm{~h}$.

In the next step, the chloride and bromide ionic liquids were transferred into hydroxides using ion resin Amberlite IRN 78. The aqueous solution of ionic liquids was mixed with an appropriate amount of ion resin under stirring. The ion exchange reaction was performed until a negative reaction on halide ions was achieved using spot test with $\mathrm{AgNO}_{3}$.

In the final stage of synthesis, imidazolium or pycolinium hydroxides were slowly titrated by addition of aqueous solutions of mandelic, caffeic or cinnamic acid until inflection point was reached. After reaching the equimolar ratio of starting compounds, water was removed using vacuum under mild conditions (temperature was less than $50{ }^{\circ} \mathrm{C}$ ). The synthesized ionic liquids were stored under vacuum with $\mathrm{P}_{2} \mathrm{O}_{5}$ for the next $72 \mathrm{~h}$. Water content was determined by the Karl-Fischer coulometric titration and was found to be less than $240 \mathrm{ppm}$.

Obtained ILs (structures presented in Fig. 1 and Table S2 $\dagger$ ) were analyzed by MS, NMR and IR spectroscopy to determine their structure and purity, and the assignations are presented in ESI Fig. S1-S63. $\dagger$ The assignation for $\left[\mathrm{OHC}_{3} \mathrm{mim}\right][\mathrm{Cl}]$ and $[\mathrm{bmim}][\mathrm{Cl}]$ are given in literature. ${ }^{30,31} \mathrm{NMR}$ spectra were recorded in $\mathrm{D}_{2} \mathrm{O}$ at $25{ }^{\circ} \mathrm{C}$ on a Bruker Advance III $400 \mathrm{MHz}$ spectrometer. Tetramethylsilane was used as an accepted internal standard for calibrating chemical shift for ${ }^{1} \mathrm{H}$ and ${ }^{13} \mathrm{C} .{ }^{1} \mathrm{H}$ homodecoupling and 2D COSY method were used routinely for the assignation of the obtained NMR spectra. ${ }^{13} \mathrm{C}$ spectra were assigned by selective decoupling technique. Mass spectrometry was performed by Waters Micromass Quattro II triple quadrupole mass spectrometer and MassLynx software for control and data processing. Electrospray ionization in the positive mode was used. The electro spray capillary was set at $3.0 \mathrm{kV}$ and the cone at $20 \mathrm{~V}$. The ion source temperature was set at $120{ }^{\circ} \mathrm{C}$ and the flow rates for nitrogen bath and spray were $500 \mathrm{l} \mathrm{h}^{-1}$ and $50 \mathrm{l}$ $\mathrm{h}^{-1}$, respectively. The collision energy was $20 \mathrm{eV}$.

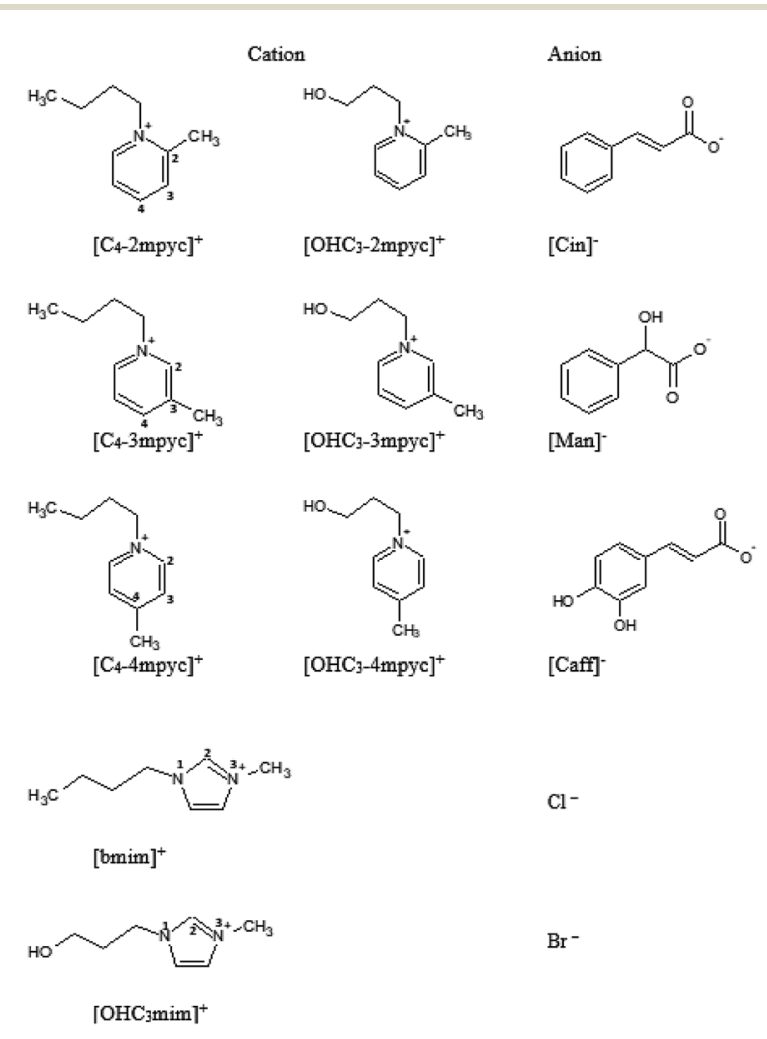

Fig. 1 Structure and abbreviations of investigated ionic liquids. 
Table 1 The diameter of fungal growth of $F$. culmorum and F. oxysporum after treatment with ionic liquids

Diameter of fungal growth $( \pm \mathrm{SD})$

IL $\quad 48 \mathrm{~h} \quad 72 \mathrm{~h} \quad 96 \mathrm{~h}$

F. culmorum

$\left[\mathrm{C}_{4}-2 \mathrm{mpyc}\right][\mathrm{Br}]$

$\left[\mathrm{C}_{4}-3 \mathrm{mpyc}\right][\mathrm{Br}]$

$\left[\mathrm{C}_{4}-4 \mathrm{mpyc}\right][\mathrm{Br}]$

$\left[\mathrm{OHC}_{3}-2 \mathrm{mpyc}\right][\mathrm{Cl}]$

$\left[\mathrm{OHC}_{3}-3 \mathrm{mpyc}\right][\mathrm{Cl}]$

$\left[\mathrm{OHC}_{3}-4 \mathrm{mpyc}\right][\mathrm{Cl}]$

$\left[\mathrm{OHC}_{3}-2 \mathrm{mpyc}\right][\mathrm{Cin}]$

$\left[\mathrm{OHC}_{3}-3 \mathrm{mpyc}\right][\mathrm{Cin}]$

$\left[\mathrm{OHC}_{3}-4 \mathrm{mpyc}\right][\mathrm{Cin}]$

[OHC 3 -2mpyc][Man]

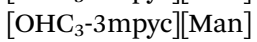

[OHC $\left.\mathrm{OH}_{3}-4 \mathrm{mpyc}\right][\mathrm{Man}]$

$\left[\mathrm{OHC}_{3}-2 \mathrm{mpyc}\right][\mathrm{Caf}]$

[OHC 3 -3mpyc][Caf]

$\left[\mathrm{OHC}_{3}-4 \mathrm{mpyc}\right][\mathrm{Caf}]$

[bmim] $] \mathrm{Cl}]$

[bmim][Cin]

[bmim][Man]

[bmim][Caf]

$\left[\mathrm{OHC}_{3} \mathrm{mim}\right][\mathrm{Cl}]$

[OHC $\mathrm{OHim}_{3} \mathrm{~m}[\mathrm{Cin}]$

$\left[\mathrm{OHC}_{3} \mathrm{mim}\right][\mathrm{Man}]$

$\left[\mathrm{OHC}_{3} \mathrm{mim}\right][\mathrm{Caf}]$

Control

F. oxysporum

$\left[\mathrm{C}_{4}-2 \mathrm{mpyc}\right][\mathrm{Br}]$

$\left[\mathrm{C}_{4}-3 \mathrm{mpyc}\right][\mathrm{Br}]$

$\left[\mathrm{C}_{4}-4 \mathrm{mpyc}\right][\mathrm{Br}]$

$\left[\mathrm{OHC}_{3}-2 \mathrm{mpyc}\right][\mathrm{Cl}]$

$\left[\mathrm{OHC}_{3}-3 \mathrm{mpyc}\right][\mathrm{Cl}]$

$\left[\mathrm{OHC}_{3}-4 \mathrm{mpyc}\right][\mathrm{Cl}]$

$\left[\mathrm{OHC}_{3}-2 \mathrm{mpyc}\right][\mathrm{Cin}]$

$\left[\mathrm{OHC}_{3}-3 \mathrm{mpyc}\right][\mathrm{Cin}]$

$\left[\mathrm{OHC}_{3}-4 \mathrm{mpyc}\right][\mathrm{Cin}]$

[OHC ${ }_{3}-2$ mpyc][Man]

[OHC 3 -3mpyc][Man]

[OHC 3 -4mpyc][Man]

$\left[\mathrm{OHC}_{3}-2 \mathrm{mpyc}\right][\mathrm{Caf}]$

$\left[\mathrm{OHC}_{3}-3 \mathrm{mpyc}\right][\mathrm{Caf}]$

$\left[\mathrm{OHC}_{3}-4 \mathrm{mpyc}\right][\mathrm{Caf}]$

[bmim $][\mathrm{Cl}]$

[bmim][Cin]

[bmim][Man]

[bmim][Caf]

$\left[\mathrm{OHC}_{3} \mathrm{mim}\right][\mathrm{Cl}]$

[OHC $\mathrm{OHim}_{3} \mathrm{~m}[\mathrm{Cin}]$

$\left[\mathrm{OHC}_{3} \mathrm{mim}\right][\mathrm{Man}]$

[OHC $\mathrm{OHim}_{3}$ [Caf]

Control

$\begin{array}{ll}35.8 \pm 3.9 & 65.0 \pm 4.8 \\ 32.8 \pm 0.5 & 56.7 \pm 1.5 \\ 32.2 \pm 1.7 & 55.2 \pm 2.2 \\ 38.2 \pm 1.0 & 68.5 \pm 3.1 \\ 37.2 \pm 2.6 & 66.5 \pm 3.4 \\ 38.3 \pm 4.4 & 69.0 \pm 5.6 \\ 28.2 \pm 2.5 & 51.0 \pm 4.7 \\ 25.5 \pm 2.1 & 47.5 \pm 2.4 \\ 23.5 \pm 1.3 & 43.8 \pm 2.9 \\ 32.3 \pm 3.8 & 61.8 \pm 4.2 \\ 39.0 \pm 2.7 & 67.5 \pm 3.7 \\ 35.0 \pm 1.0 & 66.0 \pm 1.4 \\ 40.0 \pm 3.6 & 68.8 \pm 3.8 \\ 36.8 \pm 1.0 & 67.0 \pm 1.4 \\ 37.5 \pm 4.1 & 65.0 \pm 5.8 \\ 18.5 \pm 1.0 & 32.8 \pm 2.6 \\ 8.5 \pm 2.1 & 17.3 \pm 3.5 \\ 29.0 \pm 2.5 & 52.5 \pm 2.5 \\ 32.8 \pm 5.5 & 58.2 \pm 5.9 \\ 25.7 \pm 1.9 & 46.5 \pm 3.9 \\ 12.2 \pm 5.0 & 25.0 \pm 3.5 \\ 41.0 \pm 3.2 & 78.0 \pm 2.0 \\ 47.3 \pm 2.2 & 76.5 \pm 3.7 \\ 28.3 \pm 2.5 & 56.5 \pm 5.3 \\ & \\ 14.5 \pm 1.0 & 30.0 \pm 1.6 \\ 15.0 \pm 1.4 & 30.7 \pm 2.1 \\ 15.5 \pm 1.0 & 30.5 \pm 1.3 \\ 13.5 \pm 1.7 & 33.7 \pm 3.4 \\ 12.5 \pm 0.6 & 37.3 \pm 5.1 \\ 13.0 \pm 1.4 & 39.0 \pm 5.8 \\ 12.8 \pm 0.9 & 28.7 \pm 1.7 \\ 10.7 \pm 1.3 & 26.2 \pm 1.2 \\ 13.2 \pm 0.5 & 25.5 \pm 1.3 \\ 12.0 \pm 1.4 & 29.0 \pm 0.8 \\ 12.2 \pm 0.5 & 29.0 \pm 3.8 \\ 12.3 \pm 0.9 & 26.8 \pm 3.1 \\ 10.8 \pm 1.7 & 22.7 \pm 2.8 \\ 13.7 \pm 1.9 & 30.8 \pm 2.9 \\ 13.2 \pm 1.7 & 29.3 \pm 2.2 \\ 12.5 \pm 0.6 & 20.0 \pm 0.8 \\ 9.2 \pm 1.0 & 14.7 \pm 1.3 \\ 13.2 \pm 1.2 & 23.0 \pm 2.2 \\ 11.2 \pm 1.0 & 17.5 \pm 3.7 \\ 13.7 \pm 0.5 & 23.0 \pm 0.8 \\ 9.5 \pm 1.3 & 15.0 \pm 2.2 \\ 13.2 \pm 0.9 & 22.7 \pm 2.1 \\ 10.2 \pm 1.5 & 18.2 \pm 6.2 \\ 17.0 \pm 1.2 & 41.8 \pm 3.9\end{array}$

\begin{abstract}
$86.2 \pm 3.3$
$75.5 \pm 3.1$

$73.5 \pm 1.7$

$88.0 \pm 1.4$

$87.8 \pm 3.3$

$86.5 \pm 2.6$

$69.5 \pm 6.5$

$67.0 \pm 1.6$

$64.2 \pm 2.2$

$84.0 \pm 4.1$

$87.5 \pm 2.1$

$89.0 \pm 1.5$

$89.5 \pm 1.0$

$88.8 \pm 1.5$

$86.5 \pm 5.7$

$53.5 \pm 1.7$

$26.0 \pm 3.6$

$72.5 \pm 1.7$

$76.0 \pm 4.9$

$71.0 \pm 1.8$

$39.0 \pm 4.1$

$90.0 \pm 0.0$

$90.0 \pm 0.0$

$83.5 \pm 6.2$

$40.0 \pm 2.2$

$42.3 \pm 3.4$

$42.8 \pm 5.7$

$42.0 \pm 5.0$

$47.8 \pm 8.6$

$50.8 \pm 7.1$

$35.0 \pm 5.7$

$32.8 \pm 1.7$

$33.5 \pm 2.6$

$36.2 \pm 4.2$

$34.8 \pm 5.2$

$32.5 \pm 2.5$

$28.5 \pm 5.1$

$40.2 \pm 3.6$

$35.0 \pm 5.7$

$28.2 \pm 2.4$

$19.8 \pm 0.5$

$28.7 \pm 2.9$

$28.2 \pm 3.0$

$33.7 \pm 1.7$

$21.5 \pm 0.6$

$32.2 \pm 3.6$

$25.0 \pm 5.8$

$53.0 \pm 5.3$
\end{abstract}

$120 \mathrm{~h}$

$90.0 \pm 0.0$

$90.0 \pm 0.0$

$90.0 \pm 0.0$

$90.0 \pm 0.0$

$90.0 \pm 0.0$

$90.0 \pm 0.0$

$88.0 \pm 4.0$

$84.7 \pm 1.3$

$85.2 \pm 1.3$

$90.0 \pm 0.0$

$90.0 \pm 0.0$

$90.0 \pm 0.0$

$90.0 \pm 0.0$

$90.0 \pm 0.0$

$90.0 \pm 0.0$

$75.5 \pm 1.7$

$39.0 \pm 3.0$

$90.0 \pm 0.0$

$88.0 \pm 4.0$

$90.0 \pm 0.0$

$55.2 \pm 5.2$

$90.0 \pm 0.0$

$90.0 \pm 0.0$

$90.0 \pm 0.0$

$55.5 \pm 3.1$

$53.7 \pm 3.0$

$56.8 \pm 7.9$

$56.2 \pm 8.3$

$57.7 \pm 7.6$

$62.0 \pm 7.5$

$44.7 \pm 7.4$

$49.2 \pm 2.2$

$41.8 \pm 6.5$

$48.3 \pm 4.6$

$45.2 \pm 8.9$

$44.0 \pm 6.3$

$38.2 \pm 8.7$

$51.7 \pm 5.8$

$46.8 \pm 6.2$

$38.0 \pm 2.6$

$24.5 \pm 0.6$

$37.7 \pm 2.0$

$36.7 \pm 2.4$

$43.2 \pm 2.4$

$27.2 \pm 0.9$

$40.2 \pm 3.2$

$35.0 \pm 4.1$

$60.5 \pm 3.3$

$\begin{array}{lll}90.0 \pm 0.0 & \\ 54.7 \pm 4.5 & 71.7 \pm 3.5 & 83.0 \pm 4.6 \\ & & \\ 73.5 \pm 5.2 & 82.8 \pm 2.6 & 90.0 \pm 0.0\end{array}$

\section{$69.0 \pm 2.0$}

$59.0 \pm 2.6$

$61.8 \pm 7.9$

$67.7 \pm 10.7$

$68.8 \pm 8.4$

$71.8 \pm 6.7$

$50.2 \pm 10.1$

$57.2 \pm 1.9$

$49.0 \pm 10.1$

$55.0 \pm 6.9$

$53.0 \pm 11.6$

$52.0 \pm 8.1$

$45.0 \pm 11.9$

$61.2 \pm 7.9$

$55.3 \pm 8.2$

$45.0 \pm 4.1$

$30.7 \pm 1.0$

$48.0 \pm 2.8$

$45.2 \pm 2.9$

$54.5 \pm 2.4$

$32.2 \pm 3.3$

$50.7 \pm 2.5$

$46.5 \pm 4.5$

$73.0 \pm 3.6$

\begin{abstract}
$76.2 \pm 2.6$
$69.7 \pm 4.5$

$72.5 \pm 8.8$

$77.0 \pm 9.9$

$75.5 \pm 5.9$

$76.8 \pm 5.0$

$55.0 \pm 12.9$

$66.5 \pm 3.5$

$56.2 \pm 10.4$

$63.0 \pm 7.3$

$59.5 \pm 12.7$

$59.8 \pm 10.6$

$52.0 \pm 14.5$

$68.3 \pm 8.3$

$63.8 \pm 10.3$

$54.7 \pm 0.5$

$37.7 \pm 1.7$

$57.7 \pm 2.1$

$56.7 \pm 3.2$

$66.2 \pm 0.9$

$38.2 \pm 4.9$

$62.0 \pm 1.6$

$54.7 \pm 7.7$

$84.2 \pm 3.3$
\end{abstract}

\begin{abstract}
$83.5 \pm 5.0$
$75.0 \pm 5.0$

$78.5 \pm 5.8$

$81.3 \pm 7.8$

$80.2 \pm 4.5$

$82.2 \pm 5.9$

$59.2 \pm 13.0$

$72.0 \pm 6.2$

$64.7 \pm 13.4$

$70.8 \pm 7.6$

$66.0 \pm 15.1$

$67.5 \pm 12.5$

$57.7 \pm 16.7$

$73.5 \pm 6.2$

$71.8 \pm 9.0$

$67.0 \pm 3.2$

$41.7 \pm 3.1$

$64.7 \pm 2.1$

$63.7 \pm 3.3$

$75.5 \pm 1.3$

$43.5 \pm 5.8$

$70.7 \pm 1.9$

$62.7 \pm 8.5$

$88.0 \pm 2.4$
\end{abstract}

$87.5 \pm 3.8$

$75.0 \pm 7.7$

$78.5 \pm 6.1$

$88.2 \pm 3.5$

$90.0 \pm 0.0$

$90.0 \pm 0.0$

$68.3 \pm 14.7$

$81.5 \pm 10.1$

$75.2 \pm 18.1$

$82.0 \pm 5.7$

$76.2 \pm 16.7$

$80.3 \pm 14.7$

$67.7 \pm 19.0$

$86.2 \pm 7.5$

$79.8 \pm 11.8$

$75.2 \pm 4.0$

$47.0 \pm 3.2$

$71.2 \pm 1.7$

$71.5 \pm 1.0$

$81.0 \pm 1.4$

$48.5 \pm 8.1$

$78.0 \pm 3.6$

$70.5 \pm 7.9$

$90.0 \pm 0.0$

\subsection{Antifungal activity assay}

The in vitro antifungal activities of the 23 ionic liquids against $F$. oxysporum and F. culmorum (culture collections of Chair of Phytopathology, Faculty of Agrobiotechnical Sciences Osijek, Croatia) were conducted. To test growth inhibition of investigated fungi, the Petri dishes ( $9 \mathrm{~cm}$ in diameter) were filled with a mixture of recently prepared PDA (Difco, Detroit, Michigan) and one type of selected ionic liquid. All tests were performed at a ILs concentration of $\mathrm{mg} \mathrm{L}^{-1}$. Petri dishes were filled with $10 \mathrm{ml}$ of prepared mixture. Agar plugs (4 mm in diameter) of 1 week old fungal cultures were collected with a sterilized needle and then placed in the center of the Petri dishes. Petri dishes were kept in a growth chamber at $22 \pm 1{ }^{\circ} \mathrm{C}$, with $12 \mathrm{~h} \mathrm{light} / 12 \mathrm{~h}$ dark regime. Each measurement consists of four replicates. The radial growth of the fungal colonies was measured 48, 72, 96, 
a)

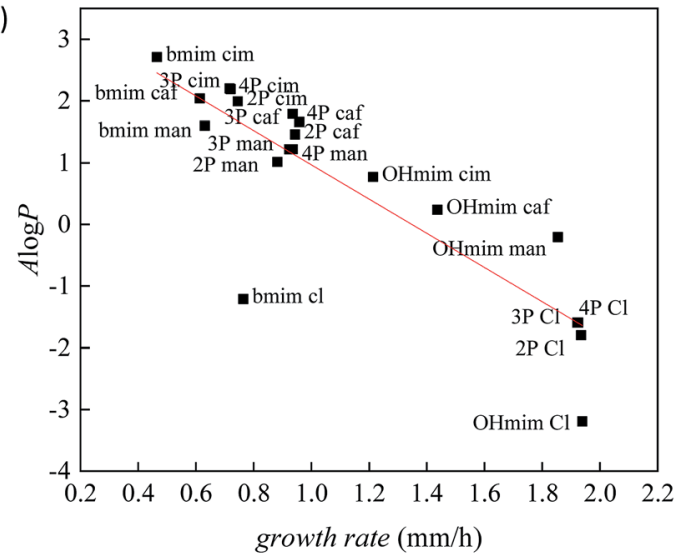

b)

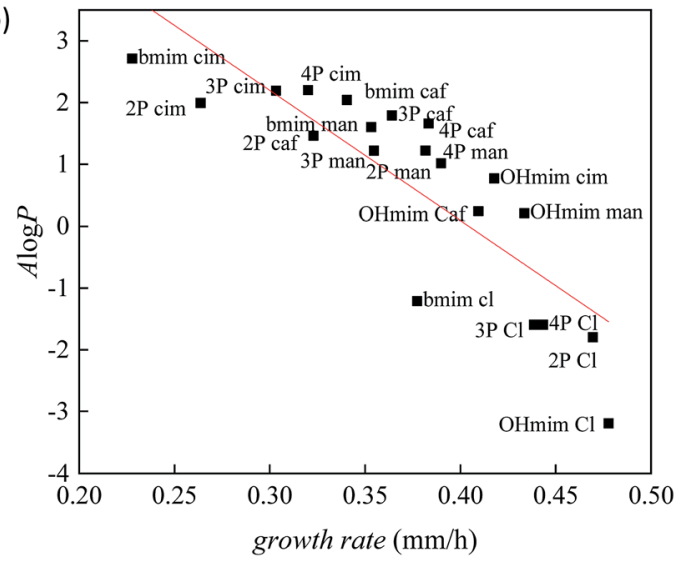

Fig. 2 The correlation between lipophilic descriptor $(A \log P)$ and growth rate for all investigated ionic liquids on: (a) F. culmorum and (b) F. oxysporum. (2P $=\left[\mathrm{OHC}_{3}-2 \mathrm{mpyc}\right]^{+} ; 3 \mathrm{P}=\left[\mathrm{OHC}_{3}-3 \mathrm{mpyc}\right]^{+} ; 4 \mathrm{P}=$ $\left[\mathrm{OHC}_{3}-4 \mathrm{mpyc}\right]^{+}$).

120, 144, 168, 192 and $240 \mathrm{~h}$ after inoculation. PDA without ionic liquids served as control.

\subsection{Statistical analysis}

All experimental data were presented as diameter of fungal growth, as the average value of 4 measurements. Experimental data were analyzed using Origin 8.1 statistical software. The statistical analysis of results were performed using one-way ANOVA (analysis of variance) technique. The significance of differences between means was assessed using the Least Significant Difference (LSD) test at the 0.05 probability level.

\subsection{Computational simulations}

The Jaguar 9.0 program (Schrödinger Materials Science Suite 2015-4 package) was used to perform density functional theory (DFT) calculations. The validity of optimized structures was checked by the Hessian analysis, which showed no presence of imaginary frequencies. The non-covalent interactions (NCI) in the obtained optimized structures were investigated and visualized by the method of Johnson et al. ${ }^{32}$ The posterior corrected hybrid B3LYP-D3 functional was used with basis set 6-31G+ $(d, p)$. The basis set superposition error (BSSE) was used, developed by the standard Boys-Bernardi counterpoise method. The free energy of solvation was calculated using the continuum solvation model based on density (SMD). ${ }^{33}$ According to this model, the solvation free energy change at $298.15 \mathrm{~K}$ can be defined as the difference between the solvent and gas electronic energies, necessitating the corresponding gas phase calculation. ${ }^{34}$ The geometry optimizations were carried out in the gas phase, also using water and octanol as solvents, with SMD model for the overall solvation effect. Based on these results, the $A \log P$ was calculated as:

$$
A \log P=\frac{\Delta G_{\text {sol (water })}-\Delta G_{\text {sol }(\text { octanol })}}{2.303 R T}
$$

where $\Delta G_{\text {sol }}$ is the standard-state solvation free energy change of a given ionic liquid in octanol or water at $298.15 \mathrm{~K}$. The standard-state solvation free energy is defined as the free energy of transfer from the gas phase to the condensed phase, under the standard state conditions.

\section{Results and discussion}

Described tests on $F$. culmorum and $F$. oxysporum were performed in order to investigate the influence of the cation structural modification, as well as the substitution of halide ion with anion based on already known antifungal compounds, on the overall ILs antifungal activity and a possibility to fine control growth of Fusarium. In Table 1 the results of radial growth of fungal colonies is presented.

\subsection{Influence of different anion}

From Table 1, it can be seen that the pycolinium ionic liquids with chloride anion shown significantly lower toxicity comparing to ILs with the same cation but with anion based on short chain $\omega$-phenylalcanoic/phenylalcenoic acid. In the literature, using of different ILs containing halide anions do not shown remarkable toxicity compared to other anions. This is also in agreement with the earlier observation by Garcia et al. ${ }^{35}$ and Zhao et al., ${ }^{36}$ who showed that the nature of the inorganic anion has a negligible effect on the ILs toxicity.

In the case of imidazolium-based cations, $\left([\mathrm{bmim}]^{+}\right.$and $\left[\mathrm{OHC}_{3} \mathrm{mim}\right]^{+}$), the caffeate and mandelate anions express similar toxic effect as chloride. On the other side, in both investigated ionic liquids based on imidazolium cations, the most prominent toxic effect express cinnamate. It is interesting to note the various effects on different Fusarium species. The addition of caffeate shows the stimulatory effect on $F$. culmorum growth at lower exposure time in contrast to the inhibitory effect on $F$. oxysporum. This effect is the most pronounced in the case of $\left[\mathrm{OHC}_{3} \mathrm{mim}\right]^{+}$cation. The aforementioned hormetic effect (i.e., stimulatory effects occurring in response to low levels of exposure to agents harmful at high levels of exposure) depends both on the nature of the organism and the duration of exposure. Similar phenomena were also observed by Ranke et al. ${ }^{37}$ and Stepnowski et $a .^{38}$ in their studies on the toxicity of ILs towards IPC-81 leukemia cells and HeLa cells, respectively. 
a)

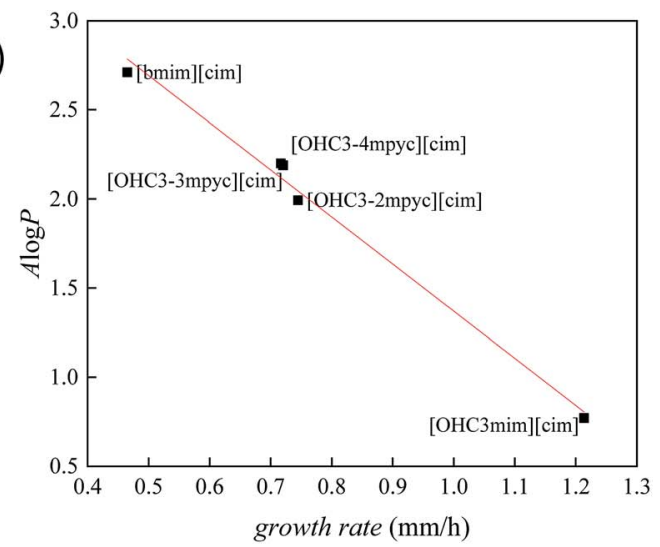

c)

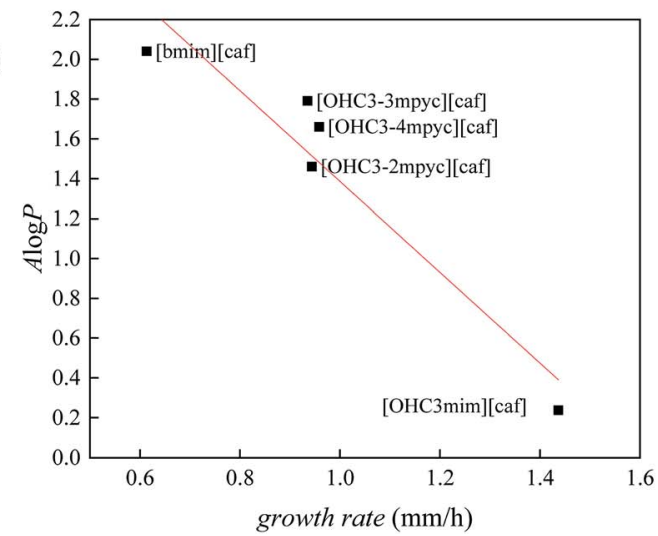

b)

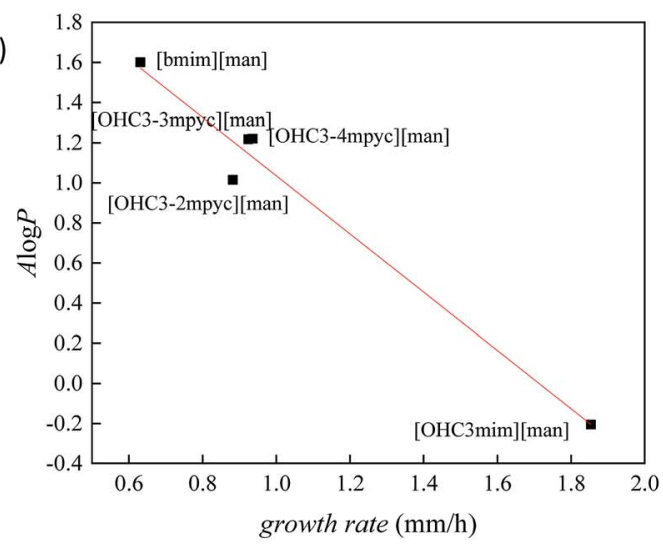

d)

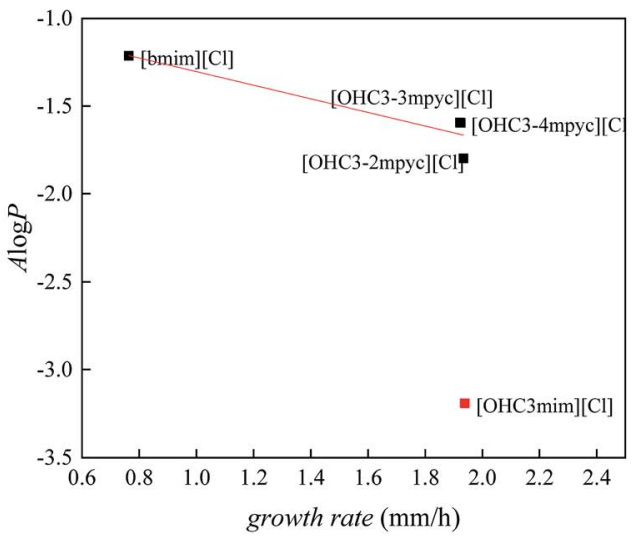

Fig. 3 The correlation between lipophilic descriptor $(A \log P)$ and growth rate of $F$. culmorum for ionic liquids containing: (a) cinnamate, (b) mandelate, (c) caffeate and (d) chloride anion.

\subsection{Influence of different cation}

As can be seen from Table 1, for all examined ionic liquids the most prominent toxic effect was expressed in the case of $[\mathrm{bmim}]^{+}$cation, as it was expected. The substitution on the terminal methyl group of the alkyl chain of the imidazolium ring with high polar - $\mathrm{OH}$ group significantly reduces the harmful effect of ionic liquids. Further, by changing the imidazolium to the pycolinium cation, inhibition of Fusarium growth was reduced even more. The same trend of less harmful ionic liquids with the introduction of the hydroxyl group in alkyl side chain can also be observed in the case of pycolinium ionic liquids. The fine-tuning of pycolinium structure, through methyl group position changing, shown an incoherent pattern for toxicity effect. This kind of structural change can be considered insignificant comparing to changes of alkyl side chain polarity and type of cation ring.

From the results presented in this work, it is obvious that alkyl side chain affects the toxicity of both imidazolium and pycolinium based ionic liquids, due to the change of their polarity. The lipophilic cations are adsorbed or intercalated in the cell membrane, causing "perturbations" in the membrane. This phenomenon can be manifested by expansion or swelling, increase in fluidity, lowering of the phase transition temperature and alteration of the ion permeability of the membrane. The presented results indicate that the presence of a lipophilic butyl group leads to destabilization of the lipid double layer membrane, which can be significantly reduced through the introduction of the oxygen as a hydroxyl group in the alkyl side chain. Furthermore, from obtained results, it is suggested that the type of alkyl chain on cation ring is the most determining factor for ILs toxicity. It is obvious that imidazolium ring is far more harmful towards Fusarium species than pycolinium ring. These results are in good accordance with literature suggesting the prominent toxic effect of the imidazolium core..$^{28,39,40}$

\subsection{The correlation between lipophilicity and growth rate}

In the literature, the lipophilicity was proposed to determine the solubility of short-chain $\omega$-phenylalcanoic/phenylalcenoic acids in bacterial membranes and thus influence their antimicrobial activity. ${ }^{41,42}$ Also, the recent research concerning ionic liquids, points out lipophilicity as one of the most important factors deciding their toxicity. ${ }^{39,43,44}$ Thus, the establishing of adequate lipophilic descriptor is of great importance. In order to deduct more precise conclusion about structural changes of ionic liquids on toxicity towards Fusarium species, the molecular descriptor $A \log P$ was predicted from DFT calculations.

On the other hand, the radial growth measurement of the fungal colonies offers only a qualitative description of toxicity. To have an opportunity to distinguish more precisely inhibition effect of various ionic liquids on Fusarium growth it is necessary 
a)

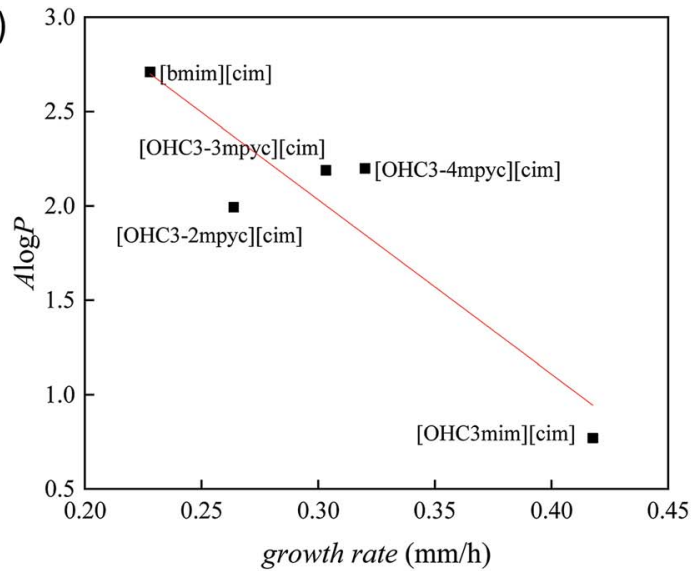

c)

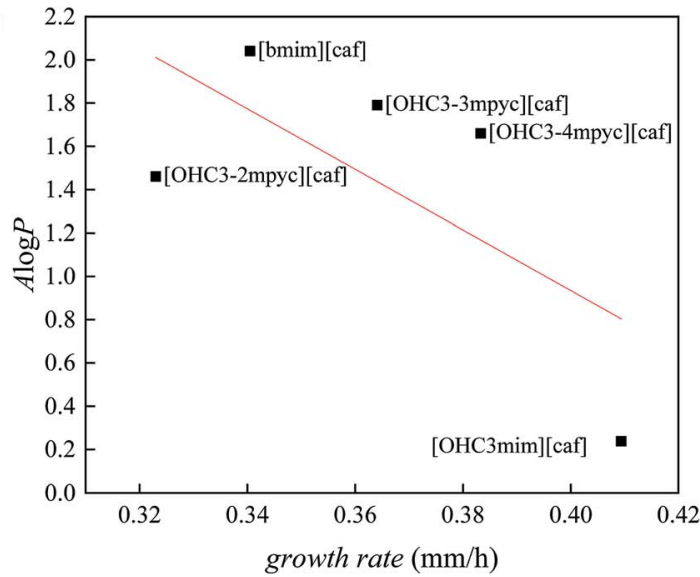

b)

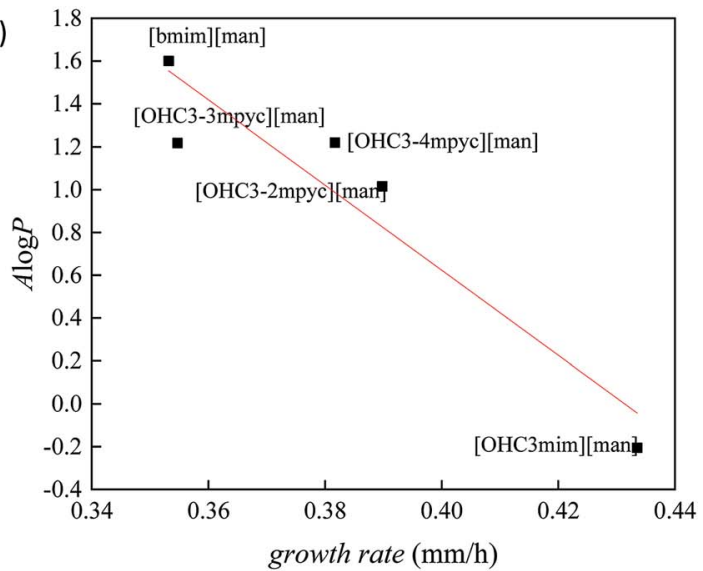

d)

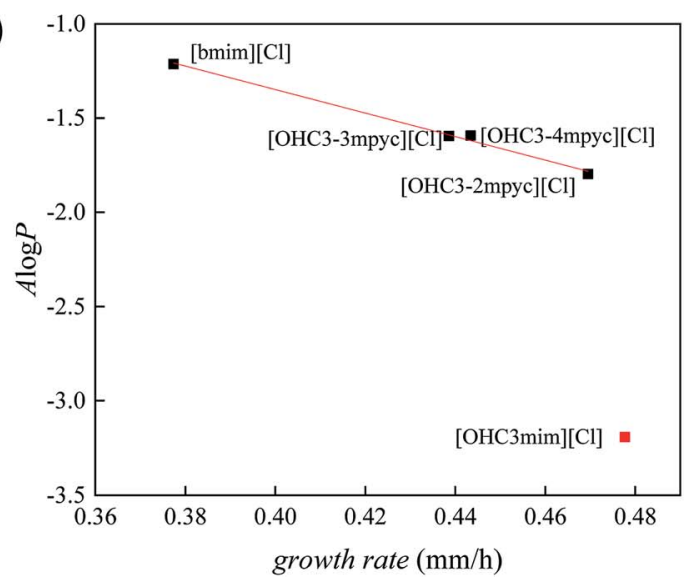

Fig. 4 The correlation between lipophilic descriptor $(A \log P)$ and growth rate of $F$. oxysporum for ionic liquids containing: (a) cinnamate, (b) mandelate, (c) caffeate and (d) chloride anion.
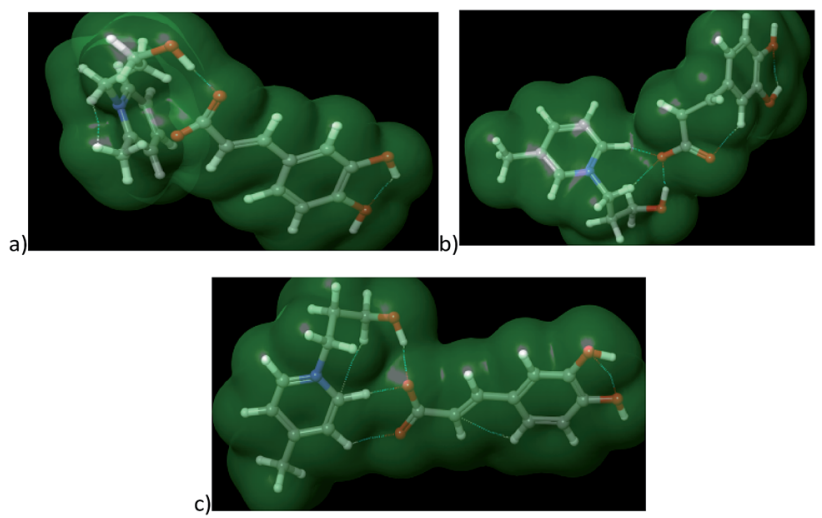

Fig. 5 The optimized structures of ionic liquids along with representation of non-covalent interactions: (a) $\left[\mathrm{OHC}_{3}-2 \mathrm{mpyc}\right][\mathrm{Caff}]$, (b) $\left[\mathrm{OHC}_{3}-3 \mathrm{mpyc}\right][\mathrm{Caff}]$ and (c) $\left[\mathrm{OHC}_{3}-4 \mathrm{mpyc}\right][\mathrm{Caff}]$.

to quantify experimental results. Therefore, in this work, the growth rate was calculated as a derivation of radial growth with observed time. In literature was confirmed that this parameter could describe a quite accurately quantitative result of disc dilution method. ${ }^{45}$
To validate the correlation between two descriptors, growth rate and $A \log P$, the results for all investigated ionic liquids are presented in Fig. 2. The Person's regression coefficient obtained using linear fit for F. culmorum is 0.859 and for F. oxysporum 0.836 .

From Fig. 2 it can be seen a trend of increasing growth rate with lower values of $A \log P$. Namely, a higher value of growth rate indicating the less inhibitory influence of an investigated ionic liquid, i.e., lower toxicity. On the other hand, the more positive values of $A \log P$ describes more lipophilic nature of the compound. All these results demonstrate the high level of the interdependency of lipophilicity and toxicity for investigated ionic liquids towards the Fusarium genus.

From Fig. 2 it can be seen that ionic liquids with cinnamate suppress the growth of Fusarium more than other ionic liquids, due to the highest lipophilicity. On the contrary, in the experiments with the most hydrophilic ionic liquids containing chloride anions, the growth of fungi was more rapid. The comparison between results obtained for ILs with cinnamate and caffeate indicate that the presence of -OH group in phenyl ring significantly promotes the growth of Fusarium due to increased polarity. Furthermore, the reduction of double bond 
strongly affects antibacterial activity, which is manifested by less toxicity of mandelates compared to cinnamates.

Comparing IL's effect on the growth of $F$. culmorum and $F$. oxysporum, it can be seen that the inhibitory influence of ionic liquids is more pronounced in the case of $F$. oxysporum. This result suggests that even though both fungi belong to the same genus, there are species specificity concerning interactions between ILs and cell membranes and their effect on overall fungi growth. The cell membrane of $F$. oxysporum is more sensitive to the presence of ionic liquids and consequently more prone to incorporate lipophilic compounds in its structure leading to disruption of cell wall and dysfunctionality of cell, leading to a smaller growth rate.

In order to better distinguish the individual effect of various cation on the growth of Fusarium, the variation of $A \log P v s$. growth rate for each anion is presented in Fig. 3 and 4 . As it was already mentioned in all ILs, $[\mathrm{bmim}]^{+}$cation express the most reductive effect towards Fusarium genus, due to highest $A \log P$ value. On the contrary, the fastest growth of investigated fungi was obtained after treatment with imidazolium ionic liquids with hydroxypropyl side chain and the most negative $A \log P$ values.

The cations with similar values of predicted polarity $\left[\mathrm{OHC}_{3}-\right.$ $3 \mathrm{mpyc}]^{+}$and $\left[\mathrm{OHC}_{3}-4 \mathrm{mpyc}\right]^{+}$shown almost same effect on $F$. culmorum growth rate, and more divergent on F. oxysporum. The only exception occurs in the case of ionic liquids $\left[\mathrm{OHC}_{3}-3 \mathrm{mpyc}\right]$ [Caff] and $\left[\mathrm{OHC}_{3}-4 \mathrm{mpyc}\right][\mathrm{Caff}]$ which shown different values of $A \log P$. The explanation for this situation can be found in optimized geometrical structures of both cations with caffeate (Fig. 5).

From Fig. 5 it can be seen that the methyl-group on position C4 influence different orientation of pycolinium cation towards caffeate anion, leading to divergent interactions than in case of methyl-group on position $\mathrm{C} 3$. Namely, the $-\mathrm{COO}^{-}$from caffeate is more accessible for interaction with $\left[\mathrm{OHC}_{3}-3 \mathrm{mpyc}\right]^{+}$, leading to stronger interactions between the polar carboxyl group and cation. This cause the better shielding of $-\mathrm{COO}^{-}$a group which additionally reduce accessible hydrophilic part of the molecule. Thus, interactions between the cell membrane and lipophilic part of $\left[\mathrm{OHC}_{3}-3 \mathrm{mpyc}\right][\mathrm{Caff}]$ is more possible, leading to a smaller growth rate of $F$. culmorum and $F$. oxysporum. This observation can also be applied to $\left[\mathrm{OHC}_{3}-2 \mathrm{mpyc}\right][\mathrm{Caff}]$ which have the smallest amount of non-covalent interactions between cation and carbonyl group of caffeate.

Consequently, hydrophilic parts of $\left[\mathrm{OHC}_{3}-2 \mathrm{mpyc}\right][\mathrm{Caff}]$ are most available for interactions, reducing the possibility of incorporation of this ionic liquid in the cell membrane. As a rule, the methylation of pycoline ring on $\mathrm{C} 2$ position caused more hydrophilic properties of ionic liquids, i.e., lower $A \log P$ values comparing to other pycoline based analogs. Due to this circumstance, the faster growth rate of $F$. culmorum can be observed for all ionic liquids containing $\left[\mathrm{OHC}_{3}-2 \mathrm{mpyc}\right]^{+}$cation. The obtained results for $F$. oxysporum shown a more incoherent pattern.

The ionic liquids containing $\left[\mathrm{OHC}_{3}-\mathrm{mim}\right]^{+}$affect the $\mathrm{Fusa}$ rium growth in the smallest amount, due to their highest hydrophilicity. As can be seen from Fig. 3 and 4, the extreme hydrophilic substance, $\left[\mathrm{OHC}_{3}-\mathrm{mim}\right][\mathrm{Cl}]$, reduce growth rate significantly more than their $A \log P$ values were predicting. Hence, these results are considered as outliers. From this observation, the proposed model cannot be applied for accurate prediction of ILs toxicity based on $A \log P$ value. In consequence, besides the lipophilicity based toxic interaction with membranes, the possibility of further and more specific modes of toxic action has to be taken into account in order to obtain a more precise model. Therefore, for compounds with high hydrophilicity, it is necessary to develop a new model based on the more detailed investigation.

\section{Conclusions}

The data collected in this research for pycolinium ILs shown significantly lower toxicity comparing to imidazolium ILs towards Fusarium oxysporum and Fusarium culmorum growth rate. The Fusarium genus growth rate was the less affected by chloride anion in comparison with well known antifungal anions, while ILs with cinnamate proved the most toxic to both types of fungi. Further, the type of alkyl chain on cation ring exhibited as the most determining factor for ILs toxicity. The findings clearly suggest that tuning of the lipophilicity of imidazolium and pycolinium cations by the introduction of polar groups in the side alkyl chain have pronounced effect on Fusarium growth rate. Also, it can be concluded that the inhibitory influence of ILs is more pronounced in the case of $F$. oxysporum. It was shown that is established good correlation between calculated $A \log P$ and experimentally obtained Fusarium genus growth rate. $A \log P$ calculated in this work could be a good predicting tool of antifungal activity.

\section{Conflicts of interest}

Authors have no any conflict of interest to declare.

\section{Acknowledgements}

This work was financially supported by the Provincial Secretariat for Higher Education and Scientific Research of APV under project contract 142-451-2766/2018-01/02, the Ministry of Education, Science and Technological Development of the Republic of Serbia under project contract ON172012.

\section{Notes and references}

1 J. Menke, J. Weber, K. Broz and H. C. Kistler, PLoS One, 2013, 8, e63077.

2 I. Plavšin, M. Velki, S. Ečimović, K. Vrandečić and J. Ćosić, Eur. J. Soil Biol., 2017, 78, 1-6.

3 B. Scherm, V. Balmas, F. Spanu, G. Pani, G. Delogu, M. Pasquali and Q. Migheli, Mol. Plant Pathol., 2013, 14, 323-341.

4 J. Lević, Vrste roda Fusarium, Cicero, Beograd, Srbija, 2008.

5 T. Duvnjak, A. Sudarić, M. Matoša Kočar, J. Ćosić and K. Vrandečić, Plant Dis., 2016, 101, 249-253. 
6 A. Rana, M. Sahgal, and B. N. Johri in Developments in Fungal Biology and Applied Mycology, ed. T. Satyanarayana, S. Deshmukh and B. Johri, Springer, Singapore, 2017, ch. 10, pp. 159-199.

7 S. Mehnaz, R. S. Z. Saleem, B. Yameen, I. Pianet, G. Schnakenburg, H. Pietraszkiewicz, F. Valeriote, M. Josten, H. G. Sahl, S. G. Franzblau and G. Harald, J. Nat. Prod., 2013, 76, 135-141.

8 M. Y. Yoon, B. Cha and J. C. Kim, Plant Pathol. J., 2013, 29, 19.

9 K. Bica, L. R. Cooke, P. Nugent, C. Rijksen and R. D. Rogers, Green Chem., 2011, 13, 2344-2346.

10 J. Pernak, R. Giszter, A. Biedziak, M. Niemczak, R. Olszewski, K. Marcinkowska and T. Praczyk, J. Agric. Food Chem., 2017, 65, 260-269.

11 J. P. Armstrong, C. Hurst, R. G. Jones, P. Licence, K. R. J. Lovelock, C. J. Satterley and I. J. Villar-Garcia, Phys. Chem. Chem. Phys., 2007, 9, 982-990.

12 A. O. Diallo, C. Len, A. B. Morgan and G. Marlair, Sep. Purif. Technol., 2012, 97, 228-234.

13 R. D. Rogers and K. R. Seddon, Science, 2003, 302, 792-793.

14 T. P. T. Pham, C. W. Cho and Y. S. Yun, Water Res., 2010, 44, 352-372.

15 M. Petkovic, K. R. Seddon, L. P. N. Rebelo and C. S. Pereira, Chem. Soc. Rev., 2011, 40, 1383-1403.

16 M. Amde, J. F. Liu and L. Pang, Environ. Sci. Technol., 2015, 49, 12611-12627.

17 M. V. S. Oliveira, B. T. Vidal, C. M. Melo, R. C. M. de Miranda, C. M. F. Soares, J. A. P. Coutinho, S. P. M. Ventura, S. Mattedi and Á. S. Lima, Chemosphere, 2016, 147, 460-466.

18 K. S. Egorova and V. P. Ananikov, J. Mol. Liq., 2018, 272, 271300.

19 M. Cvjetko Bubalo, K. Radošević, I. Radojčić Redovniković, I. Slivac and V. Gaurina Srček, Arh. Hig. Rada Toksikol., 2017, 68, 171-179.

20 R. Biczak, B. Pawłowska and J. Feder-Kubis, Environ. Sci. Pollut. Res., 2015, 22, 11740-11754.

21 B. Peric, E. Martí, J. Sierra, R. Cruañas, M. Iglesias and M. A. Garau, Environ. Toxicol. Chem., 2011, 30, 2802-2809.

22 M. Matzke, S. Stolte, K. Thiele, T. Juffernholz, J. Arning, J. Ranke, U. Welz-Biermann and B. Jastorff, Green Chem., 2007, 9, 1198-1207.

23 T. Liu, L. Zhu, J. Wang, J. Wang, J. Zhang, X. Sun and C. Zhang, Sci. Rep., 2015, 5, 18444-18454.

24 J. Pernak, K. Czerniak, A. Biedziak, K. Marcinkowska, T. Praczyk, K. Efrurt and A. Chrobok, RSC Adv., 2016, 6, 52781-52789.

25 J. Ranke, S. Stolte, R. Stormann, J. Arning and B. Jastorff, Chem. Rev., 2007, 107, 2183-2206.
26 B. Peric, J. Sierra, E. Martí, R. Cruañas, M. A. Garau, J. Arning, U. Bottin-Weber and S. Stolte, J. Hazard. Mater., 2013, 261, 99-105.

27 H. S. Wu, W. Raza, J. Q. Fan, Y. G. Sun, W. Bao and Q. R. Shen, J. Agric. Food Chem., 2008, 56, 1316-1321.

28 R. Biczak, B. Pawłowska, A. Telesiński and W. Ciesielski, Chemosphere, 2016, 165, 519-528.

29 A. F. Sänchez-Maldonado, A. Schieber and M. G. Gänzle, J. Appl. Microbiol., 2011, 111, 1176-1184.

30 A. Tot, Č. Podlipnik, M. Bešter-Rogač, S. Gadžurić and M. Vraně̌, Arabian J. Chem., 2017, DOI: 10.1016/ j.arabjc.2017.12.011.

31 S. A. Dharaskar, M. N. Varma, D. Z. Shende, C. K. Yoo and K. L. Wasewar, Sci. World J., 2013, DOI: 10.1155/2013/395274.

32 E. R. Johnson, S. Keinan, P. Mori-Sanchez, J. ContrerasGarcia, A. J. Cohen and W. Yang, J. Am. Chem. Soc., 2010, 132, 6498-6506.

33 A. V. Marenich, C. J. Cramer and D. G. Truhlar, J. Phys. Chem. B, 2009, 113, 6378-6396.

34 R. F. Ribeiro, A. V. Marenich, C. J. Cramer and D. G. Truhlar, J. Phys. Chem. B, 2011, 115, 14556-14562.

35 M. T. Garcia, N. Gathergood and P. J. Scammells, Green Chem., 2005, 7, 9-14.

36 D. Zhao, Y. Liao and Z. Zhang, Clean: Soil, Air, Water, 2007, 35, 42-48.

37 J. Ranke, K. Mölter, F. Stock, U. Bottin-Weber, J. Poczobutt, J. Hoffmann, B. Ondruschka, J. Filser and B. Jastorff, Ecotoxicol. Environ. Saf., 2004, 58, 396-404.

38 P. Stepnowski, A. C. Składanaowski, A. Ludwiczak and E. Laczyńska, Hum. Exp. Toxicol., 2004, 23, 513-517.

39 S. Stolte, J. Arning, U. Bottin-Weber, A. Müller, W. R. Pitner, U. Welz-Biermann, B. Jastorff and J. Ranke, Green Chem., 2007, 9, 760-767.

40 B. Peric, J. Sierra, E. Martí, R. Cruañas and M. A. Garau, Chemosphere, 2014, 108, 418-425.

41 F. Bisogno, L. Mascoti, C. Sanchez, F. Garibotto, F. Giannini, M. Kurina-Sanz and R. Enriz, J. Agric. Food Chem., 2007, 55, 10635-10640.

42 M. Sova, Mini-Rev. Med. Chem., 2012, 12, 749-767.

43 A. Tot, M. Vraneš, I. Maksimović, M. Putnik-Delić, M. Daničić, S. Belić and S. Gadžurić, Ecotoxicol. Environ. Saf., 2018, 147, 401-406.

44 M. Vraneš, A. Tot, S. Jovanović-Šanta, M. Karaman, S. Dožić, K. Tešanović, V. Kojić and S. Gadžurić, RSC Adv., 2016, 98, 96289-96295.

45 S. Samapundo, F. Devlieghere, B. De Meulenaer, A. H. Geeraerd, J. F. Van Impe and J. M. Debevere, Int. J. Food Microbiol., 2005, 105, 35-52. 